\title{
The Impact of Intercultural Exchange on Secondary School Exchange Students and Their Host Families
}

\author{
Manca Sustarsic \\ University of Hawai'i at Manoa, United States
}

\begin{abstract}
The last decade has seen a significant increase of international student mobility and a growing popularity of secondary school exchange programs in the United States and around the world. Drawing upon culture learning theory, the purpose of this study is to understand the impacts, challenges, and rewards of intercultural exchange on secondary school exchange students and their host families. I performed a case study of in-depth interviews with six students who were placed in Hawai'i for an academic year on the Kennedy-Lugar Youth Exchange and Future Leaders Exchange meritbased scholarships, as well as interviews with their volunteer host families. Findings show that intercultural exchange occurs as a two-way process. Both students and host families reap the benefits of intercultural exchange by way of active interaction and culture sharing that is enhanced by a positive student-host relationship. This study sheds light not only on the experiences of secondary school exchange students but also on the experiences of the volunteer host families.
\end{abstract}

Keywords: globalization, host families, intercultural exchange, international students, secondary school education

\section{INTRODUCTION}

With rapid globalization, the last decade has seen a significant increase of international student mobility. According to the Organization for Economic Cooperation and Development (OECD, 2014), 8 million students are expected to be studying abroad by 2025 . In recent years, there has been a steady increase of students on a secondary school level who decide to study abroad. Between 2004 and 2016, the 
number of these students tripled, with 82,000 international students in American high schools in 2016 (Bureau of Educational and Cultural Affairs [ECA], n.d.). Although international secondary school students account for only $0.5 \%$ of all secondary school students in the United States, their numbers are steadily growing (Institute of International Education [IIE], 2017).

In light of this increasing flow of young international sojourners who study abroad, this study sheds light on the experiences of international secondary school exchange students placed in Hawai'i as part of the two highly selective U.S. Department of State merit-scholarship programs: Kennedy-Lugar Youth Exchange (YES) and Future Leaders Exchange (FLEX). The students come from Eastern European, Eurasian, Asian, Middle Eastern, and African countries with which the U.S. government maintains good diplomatic ties. In contrast to F-1 students whose main goal is to earn American high school diploma, J-1 exchange students on the FLEX and YES programs are primarily motivated to come to the United States for cultural exchange (Farrugia, 2014) where they attend high school in the host family's district for an academic year.

The purpose of this study is to equip future participants of secondary school exchange programs with a better understanding of the culture sharing that occurs within a homestay program. It contributes to filling the gap in international study abroad literature that has neglected the experiences of secondary school exchange students as well as those of the volunteer host families. The findings also advance scholarly understanding of the experiences and impacts of state-funded scholarship programs and offer insights that might be useful for future program design such as cross-cultural training for students and host families.

\section{LITERATURE REVIEW}

Generally, student exchange programs are defined as "the international movement of scholars and students" (Harari, 1992, p. 69) with the United States as the top host country (IIE, 2017). In 2017, 21,005 students were on a short-term secondary school exchange programs, and lived with an American host family or at an accredited boarding school (ECA, n.d.). This includes the secondary school programs funded by the U.S. Department of State, such as FLEX and YES (Marklein, 2014) that are of vital importance for the U.S. government's efforts to expose foreign youth to American culture and values. Such merit-based scholarships remain an important tool of U.S. public diplomacy to promote people-to-people exchanges (Izadi, 2016; Marklein, 2014). Citizen diplomacy - engaging in cultural exchange on a personal level - is an integral part of public diplomacy with exchange students, host families, and wider host community being its agents (Bellamy \& Weinberg, 2008). According to the U.S. Department of State, citizen diplomats have "the right to help shape U.S. foreign relations one handshake at a time" (National Museum of American Diplomacy, 2019). However, Knight (2017) argued that international education should move away from diplomacy that is informed mainly by the government's selfinterests; rather it should employ knowledge diplomacy to address global issues and inequalities. For example, once in the United States, the FLEX and YES students are 
required to participate in community service (ECA, n.d.), which exposes them to various social issues in the host community.

Funded by the U.S. government and administered by the ECA, the FLEX program for secondary school exchange was established in 1993 to promote peopleto-people diplomacy with former Soviet Union countries, and has since expanded to include several countries of Eastern and Southeastern Europe. The YES program started in 2013 with a goal to maintain good diplomatic ties with predominantly Muslim countries. The selected FLEX and YES participants are regarded as the brightest students and future leaders of their home countries. They must undergo a rigorous testing process that takes about 1 year (American Councils for International Education [ACIE], n.d.-a, n.d.-b). According to the program application rules, selection is "based on merit as evidenced in a comprehensive application, teacher reference, and demonstrated preparedness for a year-long exchange experience" (ACIE, n.d.-a). Once in the United States, students are placed in a high school, where they are required "to maintain a high level of academic performance, learn about American history and society" (ECA, n.d.). Throughout the year, a local coordinator checks in with the students and host families. This structural support on the local level is of vital importance to these state-funded programs (ACIE, n.d.-a, n.d.-b).

Given that the FLEX and YES students are aged between 15 and 18, personal growth and development can be substantial after a year of exchange. The age of the international sojourner may prove more important than the length of international exposure. Lyttle et al. (2011) argued that individuals between 12 and 18 undergo "a period of meta-development, which includes comprehension of social norms and subgroups as well as increased cognitive complexity" (p. 688). While adults have developed personal identity and a sense of cultural belonging, secondary school-aged students' personal identities have not yet been stabilized (Enloe \& Lewin, 1987; Moore \& Barker, 2012; Szkudlarek, 2010). Thus, the literature suggests that adolescent students may undergo profound cultural identity changes during and after international sojourn experience (Lyttle et al., 2011; Szkudlarek, 2010).

The secondary exchange students are relatively short-term visitors to a new culture and are very likely to experience culture shock. Although each student deals with the culture shock differently, and some may be able to cross cultures faster than others, studies show that cross-cultural contacts are innately stressful (Wan et al., 1992). Most studies agree that the sooner one overcomes culture shock, the more likely one will have a positive experience of living abroad (Brown, 2008; Brown \& Holloway, 2008; Ward et al., 2005). Importantly, the exchange experience may contribute in large to positive and lasting life changes. Several studies among international students show that ultimately the rewards of an intercultural contact may outweigh its challenges (Bachner \& Zeutschel, 2009; Chamove \& Soeterik, 2006; Zhou et al., 2008). More specifically, studies conducted among high school returnees (Bachner \& Zeutschel, 2009; Chang, 2010; Soeterik, 1998; Weichbrodt, 2014; Wilson, 1993) have confirmed immediate positive cognitive changes that students realize upon reentry, such as personal growth and increased feelings of independence, confidence, and cultural awareness. A large body of literature agrees that most people who undergo cross-cultural adjustment in their childhood feel changed or different from their peers who have not experienced living abroad. (Bachner \& Zeutschel, 
2009; Chamove \& Soeterik, 2006; Hoersting \& Jenkins, 2011). Hoersting and Jenkins's study (2011) showed that becoming bicultural is a possible result of experiencing two different cultures. It occurs when "individuals reap the psychological benefits of having better interpersonal adjustment and socio-cultural adaptation" (Hoersting \& Jenkins, p. 18). This may also stem in large from a positive student-host relationship (Rohmann et al., 2014).

The literature that explores positive impacts of the international sojourn highlights that the experience of living abroad may substantially influence the sojourners' global understanding, intercultural communication skills, cognitive differentiation, intercultural awareness, sensitivity, and perception (Bachner \& Zeutschel, 2009; Brown \& Graham, 2009; Hoersting \& Jenkins, 2011; Lyttle et al., 2011; Moore \& Barker, 2012). According to the ECA's study (2009) among YES alumni, $94 \%$ of returnees embraced a positive image of the American society. Nine out of 10 reported that by sharing stories from their exchange experience, their family and friends understand Americans and the United States better. Similarly, Bachner and Zeutschel's study (2009) found that most German returnees recognized the necessity of bridging gaps between the United States and their home country. Several important studies (Hansel, 2008a, 2008b; Thomas, 2005; Weichbrodt, 2014) conducted among alumni 10-20 years following their exchange confirmed the lasting positive impact that the experience had on the alumni's intercultural skills and cultural identity. Alumni stated that because of the exchange experience they felt more comfortable encountering different cultures. Weichbrodt's study (2014) revealed that $80 \%$ of the German alumni agreed that their worldview has changed. By increased open-mindedness, they often cared to debunk common stereotypes about the host country.

An exchange year abroad may serve as a stepping-stone for future international mobility. For example, in Weichbrodt's study (2014), 80\% of 3,000 exchange alumni returned to the host country for at least 6 weeks after the exchange, which indicates the alumni's desire to seek future opportunities to either study or work abroad. Although various factors may contribute to future international mobility, nearly half of the participants in Weichbrodt's study mentioned high school exchange as one of the main reasons to go abroad. Similarly, the American Field Service's long-term impact study revealed returnees' tendency for multicultural pursuits (Hansel, 2008a, 2008b).

Homestay may be one of the most influential components of the study abroad experience for many foreign students, especially when they actively participate in a host family life (Knight \& Schmidt-Rinehart, 2010; Schmidt-Rinehart \& Knight, 2004). As per the U.S. Department of State's Exchange Visitor Program document (§ Sec. 62.25), host families in the FLEX and YES programs shall receive no monetary payment for hosting (U.S. Citizenship and Immigration Services [USCIS], 2018). The role of a host family is to provide the student with a comfortable home, three meals a day, a bed of their own, and transportation to and from school activities. What is more, the host family is expected to treat the exchange student as a member of their family, and to include the student in any family activities (ECA, n.d.; USCIS, 2018).

Very little literature engages on the homestay component of the study abroad, especially from the host family's perspective. Schmidt-Rinehart and Knight (2004) 
found that student-host interaction was limited due to the students' busy schedule with outside activities. One of the factors that caused limited interaction may be the age of these university-level participants who possess a higher degree of independence to spend time outside of the host home compared with teenage students. Knight and Schmidt-Rinehart (2010) found that active communication between students and hosts may result in increased interaction, language learning, and cultural understanding. However, the participants in their study were university students who might have prioritized their own schedule before spending time with the host family. Thus, conscious effort through task-based learning had to be made to improve the quantity and quality of the interaction (Knight \& Schmidt-Rinehart, 2010). Rodriguez and Chornet-Roses' (2014) study examined an 8-week summer program in Luxembourg. Over one third of the participants felt like guests in their host families, while the idea of becoming a family member fell short of the student's expectations. The length of the homestay was too short to develop deep relationships. As a result, students failed to adjust fully to the host family's lifestyle. However, the study by Rohmann et al. (2014) showed that host families served as informational and emotional support to Swiss secondary school exchange students who studied in the United States and New Zealand for 10 months. Findings suggest that positive intercultural contact not only increases the chances of a positive experience for both students and hosts, but the study also found that due to such positive relationship, students are more likely to reach out to an unknown member of the host community.

\section{Theoretical Framework}

According to Berry et al. (2006), acculturation is "the process of cultural and psychological change that follows intercultural contact" (p. 305). As a result, acculturation can affect individuals' affective, behavioral, and cognitive (ABC) responses to a new environment (Ward et al., 2005). Since the 1980s, social skills and culture learning became the foundation of the culture learning theory, which addresses the ABCs of transition and adaptation. Ward et al.'s (2005) culture learning model has often been used to describe various international sojourners' experiences abroad. However, this framework may also be relevant to employ to the volunteer host family.

With its origin in social psychology, the $\mathrm{ABC}$ model emphasizes the behavioral aspect of intercultural contact (Kim, 2001; Zhou et al., 2008) that falls within the purview of intercultural exchange. More specifically, the behavioral component looks at intercultural interaction, such as contact with host nationals. The affective aspect focuses on the psychological and emotional well-being of a sojourner. Debunking stereotypes and prejudice falls within the cognitive facet that evolves around sojourners' changed perceptions (Ward et al., 2001). There is no one single theory that could be applied to the study of both students' and host families' experiences; however, culture learning theory looks at the intercultural contact as it occurs in the exchange. "Social interaction is a mutually organized and skilled performance" (Zhou et al., 2008, p. 66). Furthermore, the impact of intercultural contact can be studied within sedentary communities (Ward et al., 2001) such as host families that bring an international student into their homes. 
The intercultural exchange model in Figure 1 links the cross-cultural transition with the culture-specific skills acquisition as they occur in the process of intercultural exchange. When crossing cultures, students and host families alike may benefit from learning culturally relevant social skills. As per the culture learning theory, the responses of the intercultural exchange process include the three $\mathrm{ABCs}$ that are interrelated. Intercultural exchange experience requires a great amount of adaptation for the sojourner and the host family. The outcomes are divided between psychological, which result from affective responses, and sociocultural, which are the result of behavioral and cognitive responses. The study by Zhou et al. (2008) revealed that psychological and sociocultural adaptation are interdependent and intertwined. At the micro level, it is important to note the individual level factors, such as personality, values, and language fluency that can play a major role in an individual's experience abroad. At the macro level, we may need to consider the societal level factors, such as society of origin and society of settlement.

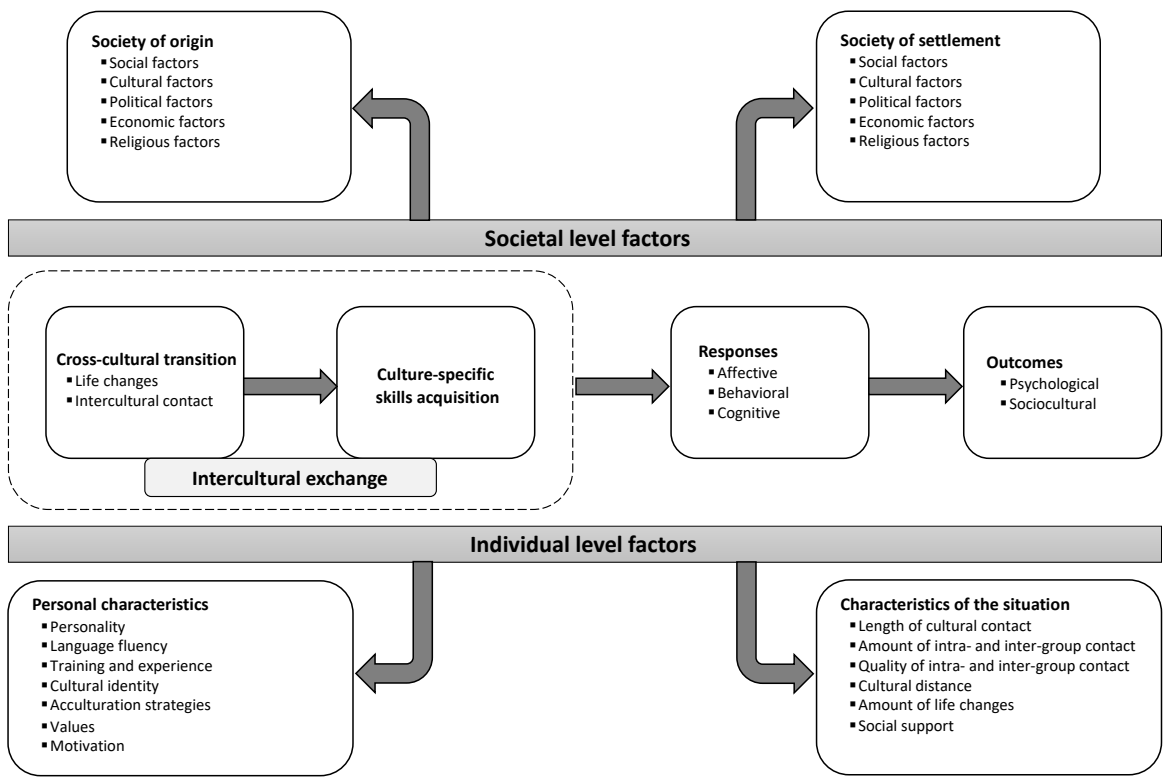

Figure 1: Factors Affecting Intercultural Exchange, Responses, and Outcomes

Note. Adapted from "Theoretical Models of Culture Shock and Adaptation in International Students in Higher Education," by Y. Zhou et al., 2008, Studies in Higher Education, 33(1), 63-75. Copyright 2008 by Taylor \& Francis.

\section{METHOD}

This research employs a qualitative case study to explore the experiences of students and host families in Hawai'i in two specific exchange programs, FLEX and YES. Case studies often look at cases within a bounded system (particular context, time, 
and place) to gain a comprehensive understanding of an issue (Stake, 2005). I used semi-structured interviews to get an in-depth understanding of the participants' intercultural experiences. To qualify for participation, students had to be current participants of the FLEX or YES programs (academic year 2017-2018), and living with a local volunteer host family in Hawai'i. The study ran at the eighth month of the exchange. The timing is important since "sociocultural adaptation follows a learning curve with a steep increase over the first four to six months" (Ward et al., 2005 , p. 66). With this assumption, the participants should have adjusted to their homestay, yet they would be able to recall the initial stages of the exchange experience.

When this research took place, a total of 15 FLEX and YES exchange students were residing in the state of Hawai'i. Due to availability and efficiency in time, I used purposeful sampling to select a diverse group of students who may "purposefully inform an understanding of the research problem and central phenomenon in the study" (Creswell \& Poth, 2018, p. 308). Six different countries across four geographical regions allowed for a heterogeneous sample. After identifying the students, I contacted their host families to seek their consent to participate in the study. One host parent in each host family volunteered to conduct the interview. I selected a total of 12 participants, six students and six host families.

The interviews were audiotaped and took about 45-60 minutes each. I interviewed two students in person at the exchange organization's office. I conducted four interviews via a Skype video call based on the participants' location. Considering families' busy schedules and distance, I conducted all interviews with host families over the phone, which is an alternative approach to access hard-to-reach participants (Sturges \& Hanrahan, 2004). However, some of the limitations of telephone interviewing compared with in-person or video conferencing are that body language cannot be observed, and participants may generate short answers or may be cut off in the middle of a thought (Arksey \& Knight, 1999). I first transcribed the data and then coded it to identify emerging themes both individually and across the interviews. Member checking guaranteed credibility and trustworthiness of the themes (Creswell \& Poth, 2018).

\section{Participant Characteristics}

As shown in Table 1, I interviewed three FLEX and three YES students. Four students were female and two were male. The average age of the participants was 16.7. Students came from Bangladesh, Georgia, Kazakhstan, Lithuania, Palestine, and Tanzania. Four students were placed with host families on the island of Oahu, and two on the Island of Hawai'i (Big Island). Three students switched host families during the exchange. It is common for a family to sign up as a welcoming host family for the first few months due to various personal reasons that may allow only for shortterm hosting. 
Table 1: Individual Characteristics of Exchange Students

\begin{tabular}{lllllll}
\hline Variable & Student 1 & Student 2 & Student 3 & Student 4 & Student 5 & Student 6 \\
\hline Gender & F & F & M & F & F & M \\
Age & 17 & 17 & 17 & 16 & 17 & 16 \\
Program & FLEX & FLEX & FLEX & YES & YES & YES \\
Country & Lithuania & Georgia & Kazakhstan & Tanzania & Bangladesh & Palestine \\
Placement & Oahu & Oahu & Oahu & Oahu & Big Island & Big Island \\
\hline
\end{tabular}

Three host families, as shown in Table 2, are multigenerational with host parents, children, and grandchildren who live in the immediate vicinity, and who are also involved in the exchange experience. Two of these families were still working, while one was retired. The other three host families were retired single hosts.

Table 2: Individual Characteristics of Host Families (HF)

\begin{tabular}{|c|c|c|c|c|c|c|}
\hline Variable & HF 1 & HF 2 & HF 3 & HF 4 & HF 5 & HF 6 \\
\hline HF type & $\begin{array}{c}\text { Three } \\
\text { generation }\end{array}$ & $\begin{array}{c}\text { Three } \\
\text { generation }\end{array}$ & $\begin{array}{l}\text { Single host } \\
\text { father }\end{array}$ & $\begin{array}{l}\text { Single host } \\
\text { mother }\end{array}$ & $\begin{array}{c}\text { Single host } \\
\text { mother }\end{array}$ & $\begin{array}{c}\text { Three } \\
\text { generation }\end{array}$ \\
\hline $\begin{array}{l}\text { Years } \\
\text { hosting }\end{array}$ & 20 & 27 & 1 & 20 & 30 & 20 \\
\hline $\begin{array}{l}\text { Exchange } \\
\text { students }^{\mathrm{a}}\end{array}$ & 6 & 15 & 1 & 3 & 8 & 16 \\
\hline
\end{tabular}

Note. $\mathrm{HF}=$ host family.

${ }^{a}$ The number of secondary school exchange students that host families hosted in previous years until now. Participants on programs other than secondary school exchange such as FLEX or YES that some of the host families may have hosted are not counted.

\section{RESULTS AND DISCUSSION}

\section{Understanding Host Families' Volunteer Motivations}

All interviewed host families were highly educated and well-traveled. Most of them had some years of experience living abroad and may have been, as such, more open-minded since they had themselves experienced being a stranger in another country. Common motives to host exchange students among the interviewees included learning about different cultures and lifestyles, and extending American hospitality to young students by making them feel welcomed and part of the family.

The single hosts in particular indicated that companionship and being surrounded by young and smart people with leadership potential drove their desire to serve as hosts. Several hosts mentioned that they liked the idea that FLEX and YES students come well-prepared, and are oriented and monitored throughout the year by the local coordinator and by the U.S. Department of State. One host felt that "there is structural support not only for the host family but also for the student." Another host added, "I 
always expect they are going to be great. They just are superior, good students. Usually they have a good command of English."

Most host families indicated no particular preference for gender, country, or religion of their students. Some hosts preferred students who were not too young, e.g. over 16 years old, while others preferred a specific gender based on previous good experiences. Some hosts started off with students from countries with which they were familiar, where they previously had lived or visited. However, after many years of hosting experience, families seemed to become more open to other countries or religions, as they wanted to learn something new from each student they hosted. As per one host, "I have been kind of open, I like something I have not experienced before."

As shown in Table 2, five out of six host families had been involved in hosting for over 20 years. All of them started off hosting for short-term programs, such as weekend or week-long homestays. Only one of them indicated that they had begun as a paid host for another program, which at that time complemented the income. However, once the host recognized the value of intercultural exchange for the whole family beyond monetary reward, they continued to host voluntarily. As per the host father's words, "I got used to having them with me. My kids got used to have exchange students in the house." These host families recognized the positive impact that intercultural exchange brought into their lives, which served as the main drive to continue hosting.

Two of the host families had hosted over 15 secondary school exchange students over the last 20 years. I could sense the pride when they shared stories of keeping in touch with most of their "children," as they often referred to their former students. One of the host families shared this sentiment excitingly: "We see their children, their husbands. And we see their weddings and then they have babies. It is really fun and we consider them all our extended family." These families valued the relationship they established during the exchange that could be the beginning of a life-long friendship.

\section{Intercultural Exchange Experiences of Exchange Students and Their Host Families}

As illustrated in Figure 2, a number of themes emerged on both sides that correspond with the culture learning theory and its $\mathrm{ABC}$ responses. Improved English language skills, increased intercultural competence, independence, and maturity are commonly identified as life-changing developments after sojourners' experience abroad. In line with culture learning theory and the studies that have focused on cognitive factors (Bachner \& Zeutschel, 2009; Chamove \& Soeterik, 2006; Chang, 2010; Hoersting \& Jenkins, 2011; Jang \& Kim, 2001; Wilson, 1993), students in this study emphasized personal growth and development as one of the personal impacts of the exchange. The Palestinian student felt that he knew himself better now. Likewise, the Georgian student shared that "the most important thing that I learned here, what I realized is just be who you are." As per the Kazakh student's observation, he became "more self-reliant, more versatile and more prepared to do anything in life." As observed in the literature on cognitive changes, such profound changes in 
identity development during the international sojourn may be related to the adolescent age of these students (Szkudlarek, 2010).

Multigenerational host families stressed the importance hosting had on their children and grandchildren. While having a foreign student in their home, one host

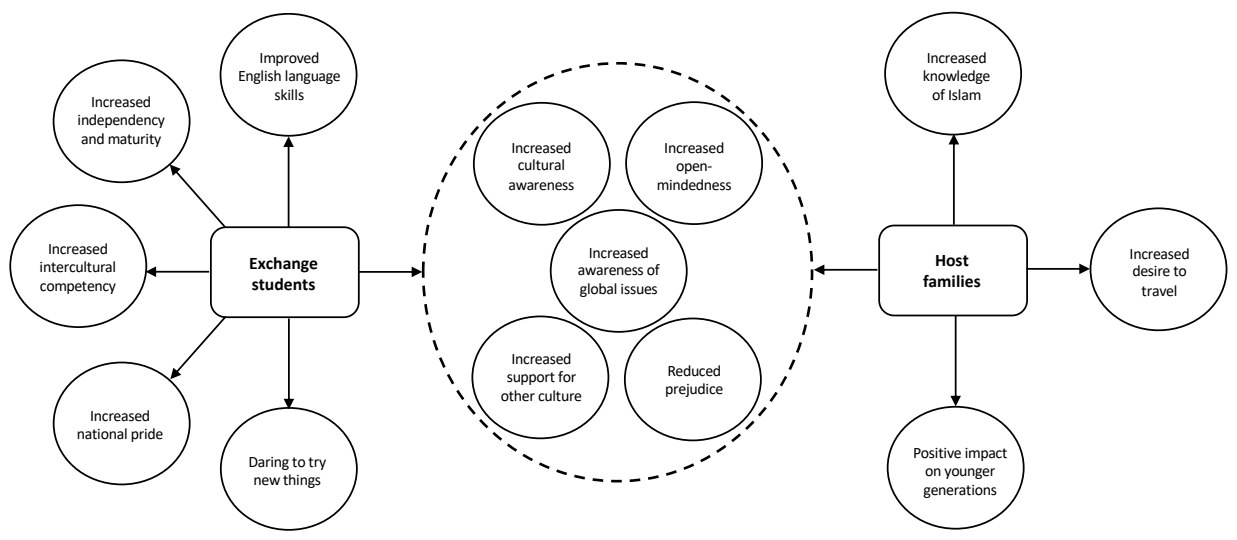

Figure 2: The Impacts of Intercultural Exchange on Exchange Students and Host Families

said that hosting "has provided my granddaughter with older sisters. And for my adult kids, they enjoy the exchange students as much as we do. [...] They really become a part of our extended family." Another host noted that their grandchildren, "now have an experience. They know there are other people who live in different places around the world and they learn about differences in the cultures." Thus, it is not only foreign student who benefit from intercultural contact with the host, but it may also be the extended host family that reaps benefits from the exposure to the foreign student. The culture learning theory stresses the importance of interaction between a sojourner and host nationals, which can result in fewer social difficulties (Ward et al., 2005). This may improve both students' and host families' intercultural competence and overall facilitate a more positive adaptation during the sojourn.

The following five themes emerged as a result of the homestay experience between students and host families: increased cultural awareness, increased openmindedness, increased awareness of global issues, reduced prejudice, and increased support for each other's country.

\section{Increased Cultural Awareness}

Most students acknowledged that they experienced culture shock in the initial stages of their stay in Hawai'i. They had been heavily influenced by American movies and felt that life in Hawai'i fell short of their expectations. As per the Tanzanian student's realization: "I expected it to be more like mainland. I also expected all people to be OK, but when I came to Hawai'i I found homeless people. International problem." Students admitted that they expected Hawai'i to be more westernized with 
White Americans inhabiting the islands. However, they came to embrace the unique cultural diversity in Hawai'i. Not only did students learn about American, Hawaiian, Asian, and Polynesian cultures that coexist on the islands, they also built pride in their home culture by sharing it with others, which was similarly found in Wilson's study (1993). As per the Bengali student's reflection:

After the first two months here I started thinking about my own country. I think I started to appreciate my country and culture better. When I am home it is just everyday stuff, but here I realized how unique it is and the long history behind it.

Although all students shared photos, videos, books, and food from their countries with host families, the most culture sharing occurred over dinner conversations when students and hosts interacted and shared stories about daily life. These often advanced into culture sharing discussions that resulted in meaningful student-host interaction, and overall seemed to ease the cultural adaptation process. The student from Kazakhstan shared that during discussions, "He [host father] tells me about America and I tell him about my country." The Georgian student claimed that "communication is the key." Active interaction with her host parents helped this student adjust well to the daily life in Hawai' $i$ :

Very often we have meaningful discussions. They [host parents] are very clever, very intelligent. I love talking with them because they teach me a lot of things starting from English to a lot of things like life. They give me motivation, and [they] give me advice on how to make my life better. So yes, discussions are one of the biggest things in my life with them.

The culture- and life-sharing discussions correspond well with the behavior component of the culture learning theory that states that "overseas students can benefit from interaction with host nationals socially, psychologically and academically" (Zhou et al., 2008, p. 70).

Host families, likewise, benefited from learning more about their student's culture. By increased cultural awareness hosts may also get to know their own culture better, which relates well with the culture learning theory (Ward et al., 2001). The host family of the Georgian student shared:

We have learned from this student so much about the culture, the way people see things and the way people behave and expressions. Americans tend to be more animated and more open. We have learned that Georgians tend to be a little more closed and subdued.

\section{Increased Open-Mindedness}

A year of living in a different culture may have students test their openmindedness as they get exposed to new or unfamiliar things. By joining the host family activities, this sometimes means that students need to get out of their comfort zone. As per the culture learning theory and transformative learning theory (Taylor \& Merriam, 2008), open-mindedness is an important life skill that sojourners acquire 
while living abroad. The transformative learning theory argues, "When a sojourner moves to another culture to live for an extended period, they often experience a transformation out of a necessity for survival and a need to relieve stress and anxiety" (Brown \& Graham, 2009, p. 82). Unlike several studies conducted among universitylevel students who indicated lack of engagement and interaction with the host family as one of the common problems (Knight \& Schmidt-Rinehart, 2010; SchmidtRinehart \& Knight, 2004), the FLEX and YES students in this study were encouraged by the program, and perhaps partially due to their adolescent age, joined host family activities and helped with family chores.

All student participants reported becoming more open to trying new things. For students who could not swim or had a fear of water, going to the beach in Hawai'i presented a big challenge. Nevertheless, the Tanzanian student signed up for swimming lessons with the help of her first host family who considered beach activities as important family events. Two other students tried out paddling and Tai Chi, activities that were, likewise, introduced to them by their hosts. In addition, students admitted to becoming less picky with food, especially when dining out with the host family. This was well-articulated by the Lithuanian student:

I learned how to try on new things, because in Lithuania I would get the same things in a restaurant. I would not experiment a lot. And here, I eat raw fish and that mochi thing. It is very interesting. I became more open-minded.

Often, students joined their hosts to attend a religious institution different from their own. For some of international students this may present a challenge, yet this study's YES students who were all Muslim, proved to be open-minded to the new experience. As they described, going to church with their host families was an opportunity to broaden their worldview, to socialize, and possibly, to expand their host national network, which is one of the vital components of the culture learning theory (Ward et al., 2005). Frequent interaction with host nationals, such as with host family and host community members, may bring emotional benefits and overall better psychological adjustment (Ward et al., 2005). Moreover, when the student-host relationship is of good quality, the willingness to explore the host environment is higher (Rohmann et al., 2014). The Bengali student shared her own experience:

Even though none of us is Christian, we went to church for Christmas and Thanksgiving shows. There I met a lot of random people just sitting beside me talking about the show. And I think this has helped me meeting a lot of people, just socializing with them.

Host families may also expand their open-mindedness by trying out traditional foods prepared by their students, and by getting more receptive to other religions, different ways of living, and different worldviews of their students. As per one host: "Sometimes we like to think that everybody thinks the way we do. You just learn that there are different perspectives and that these different perspectives should be recognized and respected."

In addition, the hosting experience increased host families' desire to travel, particularly to their students' home countries that they would never have considered before, either due to the distance or current political situation. For instance, the host 
father of the Palestinian student wanted to visit Palestine because "it is an area of the world, Middle East, that I have never been to." Such change in attitude and openmindedness on the host families' behalf corresponds with the cognitive responses of culture learning theory (Ward et al., 2001).

\section{Increased Awareness of Global Issues}

For all student participants, community service involvement set the stage for increased awareness of not only local issues in Hawai'i but also global issues. Many studies have found that the experience of living abroad enhances one's global understanding (Bachner \& Zeutschel, 2009; Brown \& Graham, 2009; Hoersting \& Jenkins, 2011; Lyttle et al., 2011; Moore \& Barker, 2012). Although FLEX and YES programs require students to complete at least 20 hours of community service during the exchange, most students in this study completed well over 50 hours. Moreover, students genuinely embraced this idea to the point that they wanted to start community service clubs back home. Most of them got involved through school clubs or with the help of their host families. The Lithuanian student explained her newly found passion for environmental issues: "I am not using any plastic straws. I am not using any plastic zip lock bags. Even one thing can make a difference. I think this never occurred to me before. It became something that I am passionate about."

As per ECA (n.d.), the international exchange students are regarded as future leaders of their countries. By increased awareness of global issues through active participation in community service, participants of this study may have developed leadership skills. With hands-on experience, students may undergo cognitive changes in attitude and behavioral responses that trigger them to take action during their exchange experience and most importantly, upon reentry to their home country. The studies among alumni have shown that the exchange experience in the United States made YES alumni (ECA, 2009) and alumni in Wilson's study (1993) think of ways to apply new skills stemming from the American culture, such as community service, to benefit the society at home. The Tanzanian student's motivation captures this well:

Before coming here, I did not think of those kinds of issues, because I am eating well. So, I did not think of anybody going to bed without food. I wish I could make the global issues club back home.

In addition, most students reported that they followed the international news more often. Students and hosts agreed that they enjoyed discussing politics of the United States and of the students' home countries. Some hosts found it important to share with the student what was happening in the United States politically. Articulated well by the Palestinian student's host father, host families may become more attuned to the pertinent issues in the student's home country:

I have become very much aware of the problems and what is happening now in Palestine and the Gaza strip over there and confrontation between Palestinians and Israelis. It made me very aware of conflicts that impact the lives of these students. 


\section{Reduced Prejudice}

Both students and host families indicated that the intercultural exchange reduced their prejudice about other cultures and religions. This corresponds with the cognitive response of culture learning, as increased positive contact with a host national may decrease perceived prejudice (Zhou et al., 2008). In a homestay environment, students and hosts get familiar with each other's lifestyle. Most students noted that they held a certain degree of stereotypes about Americans before coming to the United States. The Tanzanian student expected the United States to be more racist. The Kazakh student thought that he could understand the United States much better, and could see that "stereotypical things were not true." Studies conducted among the YES alumni (ECA, 2009) indicate that once students experience living in the United States, they may embrace and share some of the American values with their family and friends back home.

As opposed to the students on the mainland United States, the benefit for the students placed in Hawai'i was learning about various Asian and Polynesian cultures that coexist on the islands. For example, the student from Georgia changed her opinion about Japanese as she realized that "you cannot blame the whole country because of ten people. And I realized how great Japanese people are. I just learned so much because of that diversity here." Likewise, the Bengali student said, "I think I have gotten to be less stereotypical. I have just learned to never assume. I have just learned to accept that people are different." These findings correspond with studies on intercultural contact that show that positive contact with host nationals is likely to reduce prejudice (Rohmann et al., 2014).

The host families indicated becoming more tolerant towards different cultures and religions. Having a foreign student in their home for a year allowed them to experience foreign culture first-hand. Some hosts said that they became more understanding of nondemocratic political systems. For example, the host father of the Kazakh student acknowledged that his student "has different political values, because they have dictatorship"; however, this did not distract in any way from the relationship they established. The families that hosted YES students all mentioned learning more about the Islam religion. The host of the Tanzanian student in particular enjoyed when her student shared Islamic traditions and stories from the Quran. She said: "Having conversations about religion now is very informative. Especially with Islam I think Americans do not know many things about it except it must be bad." These two examples demonstrate that hosts may benefit from cognitive changes in attitudes toward different political systems and religious groups.

Also, hosts became more aware of the stereotypes that foreigners perceive about Americans. One host raised the issue of common misconceptions: "There is a stereotype of what Americans are. You know we are all blond-haired and blue-eyed and we eat potatoes and steak for dinner." Tolerance and cultural relativism are based on the assumption that no single culture is superior to another culture (Hofstede, 1991). This can be seen from another host family's comment:

I think it is important for Americans to experience foreigners because we have a tendency being surrounded by ocean on both sides of the continent, 
and the mentality that we are first or that we are the biggest and more powerful.

Being able to discuss difficult topics such as politics and religion was significant, especially given the young age of this study's participants. This choice of topics may indicate a high level of proficiency in English language among students, as well as a certain degree of comfort and trust in a student-host relationship to be able to discuss such issues. This finding adds to the importance of the quality interaction in a homestay, as articulated in the Knight and Schmidt-Rinehart study (2010) in which students struggled to talk about difficult topics with their hosts.

\section{Increased Support for Each Other's Country}

Students grew fond of their life in Hawai'i. Some embraced the culture by learning the Hula or ukulele, two staple traditions of the Hawaiian culture. The Georgian student said: "I feel like I belong here. I am calling myself like I am Hawaiian and everybody does. Sometimes I feel like I am representing Hawai'i more than my country." The Lithuanian student felt that she has learned a lot about the United States and may struggle upon reentry, because people back home may not understand why she wants to discuss the events that pertain to the United States. Despite initial denial, most students recognized that they might experience reverse culture shock once they returned home, because they had gotten used to the American lifestyle. The Georgian student explained her feelings about re-entry: "I think as soon as I go back, I will miss my life here. And whenever I have a sad moment in life, I will miss Hawai'i and being here."

Overall, all students indicated that their experiences in Hawai'i exceeded their expectations. After returning home for at least 2 years, as required by the $\mathrm{J}-1$ visa, students wished to be able to study abroad again. Half of them hoped to return to the United States; however, despite their positive experiences in Hawai'i, students felt more open and prepared for future multicultural pursuits elsewhere. These findings are similar to the studies among alumni. Compared to their immobile peers, students who return from studying abroad may feel equipped with skills such as independence, courage to try new things, leadership skills, and open-mindedness to explore the world, which may ease their adjustment period during any future international sojourn (Hansel, 2008a, 2008b; Weichbrodt, 2014).

Host families grew supportive of their students' home countries. This stemmed in part from an increased understanding of the student's culture, which can result in behavioral responses (Ward et al., 2001). Some hosts felt strongly about speaking up for the student's religion, especially when they heard people spread misinformation. The host mother of the Bengali student commented on the misconceptions people have about Islam:

When I hear people make statements that are judgmental, I speak up. Whereas in the past, I think I would be just "Yeah, yeah, yeah" and let it go. And now I need to correct some of these misconceptions. 
The host family of the Lithuanian student summed up this idea by saying, "When you host you begin to care about geographical areas, even if you never thought about them before."

\section{Rewards and Challenges of Intercultural Exchange}

For most students, culture shock presented the biggest challenge in the first few months. A positive sign of the adjustment to their homestay is that students reported very little homesickness, which was mostly credited to the initial stages of sojourn. This was often due to receiving the host national's social support or affective adaptation (Zhou et al., 2008). Many studies (Grove \& Hansel, 1983; Hoersting \& Jenkins, 2011; Wilson, 1993) attribute positive adjustment to increased acceptance of cultural differences. Also, positive intercultural contact is closely associated with one's overall satisfaction (Zhou et al., 2008). In this study, both students and host families admittedly demonstrated so.

Furthermore, studies about the affective component of the culture learning approach state that psychological and sociocultural adjustment issues occur mainly during the early stages of the sojourn, and then decrease over time (Ward et al., 2001). Having been treated as a real member of the host family has proven a significant factor that facilitated positive adjustment. The Georgian student said: "I feel $100 \%$ part of the family. I just love being with them. I feel like they love me too. I feel like they treat me as their little sister." This strong sense of belonging to one's host family was achieved through active participation in host activities and chores over the course of the year. This is in contrast to the extant research, such as the Rodriguez and Chornet-Roses' study (2014), in which students could not move beyond guest-host relationship.

Three students switched their host families during the year. Two of them had to do so because their first family signed up as a welcoming host for the first few months. The Palestinian student had to request change with the local coordinator's help due to unexpected personal disagreements with his first family. The role of the local coordinator is to recruit host families, to monitor the exchange experience, and often to serve as a mediator between student and host. When this student moved to his new host, he admitted that open communication and active participation proved to be the key to success:

We communicate well. We work together around the house, in the garden. I did not have any problems since I came here with my host family. We agree to a lot of things. And we are like even more friends than a family. We are very open to each other.

In addition, the Tanzanian student appreciated the time spent with her first host family: "I shifted family but still I communicate with my first host family, and I send some pictures to them. So, I still communicate with them." All of these students found it challenging and stressful at the time, but they realized that they had grown and become more adaptable from this experience.

Sometimes students, being placed in a family that has hosted for many years, felt like they were just one of the exchange students, and not "the one." Nevertheless, 
these families cared about each and every student they hosted, and usually wished to continue a life-long friendship with all of them. Increased social and emotional support by a host family is part of the affective response of culture learning theory that contributes to the enhanced psychological well-being of a student (Zhou et al., 2008).

Internal family dynamics may play a role in shaping the student-host relationship. Families with children may face jealousy issues as the attention suddenly gets divided among the children. Most hosts agreed that the reward of having their children and grandchildren exposed to different cultures outweighed such challenges. While working families may have struggled to dedicate quality time to the exchange student, and may have even felt guilty for this, single hosts often felt like they were "boring" or "not the perfect host family." As it may be expected from adolescent students, most of them hoped to be placed in a traditional home with two parents and children of similar age. However, this rarely happens. Those students who imagined such a family were initially disappointed to be placed with a single host. As per the interviews, all those students now appreciate the attention and care they received from the single hosts. They seem to have developed a close bond, more of a friendship than of a parent-child relationship. One student said that he saw his host father "like an older brother." Students felt this friend-like relationship showed most when hosts asked their opinion and respected it. This theme was supported by the hosts themselves. As per one host father: "We have become very good friends." Nevertheless, the host families tend to act as parents when needed, which was described by the Tanzanian student: "If I do something wrong, she will treat me like her daughter. So, I feel like I am part of the family because she cares if I did something wrong."

Finally, the true value of the intercultural exchange came into play when the student, despite the challenges, felt like a real member of the family, which came with both responsibilities and rewards. Likewise, when a host family treated a student as their own child, they would miss their presence when they leave. As per the host of the Lithuanian student:

Because she has fit in so well with our family, she is going to leave a huge hole. Just the fact that she will not be in the bedroom, she will not be going to school in the morning, she will not be somebody that we have to include in the family... It is really like a family member growing up and going away to college.

\section{CONCLUSION}

This qualitative study explored the experiences of the FLEX and YES secondary school exchange students placed in Hawai'i and their matched host families. The aim was to show that intercultural exchange occurs as a two-way process between students and their host families. Indeed, this study found that both groups reaped mutual benefits of the intercultural exchange as they learned from each other by living together in a homestay where the culture-sharing occurred on a daily basis. Active participation in host family activities and interaction that revolved around topics of 
culture, politics and religion seemed to enhance the positive student-host relationship. In addition, host families often served as emotional and social support to students. The most significant finding, though, is that students and their hosts reaped a number of common benefits through intercultural exchange. These included increased cultural awareness, open-mindedness, awareness of global issues, and support for each other's country, and reduced prejudice. With proper structural support that students and volunteer host families receive throughout the year, the state-funded exchange programs such as FLEX and YES may yield outcomes that are different from private exchange programs that lack government support.

Drawing upon the culture learning theory, this study incorporated both students' and host families' intercultural contact and experience. The ABC responses to the intercultural contact through intercultural exchange showed that these responses were interrelated and intertwined. Psychological and sociocultural outcomes of intercultural exchange could be observed among both groups; however, the emphasis of this study is put on the sociocultural impacts that largely resulted from behavioral and cognitive responses. For students, some of the immediate life-changing outcomes included personal growth and development, as well as improved English language skills, which fell within the most important cognitive changes. The behavioral and social adaptation was mainly seen in increased intercultural competence that students attributed in large to the homestay environment. These newly acquired sociocultural skills may prove helpful to these students in easing the adjustment in possible future international pursuits. Since this study took place in Hawai'i, its cultural uniqueness that students experienced contributed to increased multicultural awareness that extended to Hawaiian, Asian, and Polynesian cultures.

One of this study's limitations is its small and limited sample of students and host families. A bigger sample would allow for possible cross-country or crossgender comparisons, among others. Another limitation might be that participants who agreed to be part of this study did so due to the mostly positive experiences. Students and host families were self-selected. All host families were highly educated and welltravelled, which may attribute to increased open-mindedness from the get-go. In addition, all host families except one identified themselves as experienced in hosting. As such, they may have been keen on emphasizing the positive experiences they recognized in the value hosting has had on their lives.

One limitation of the culture learning theory is that it does not consider host families as possible beneficiaries of intercultural contact and exchange. Thus, the framework should expand to include various groups of people who are immersed in foreign cultures daily, even if it occurs in their homeland. Despite the small sample size, this study aims to contribute to future development of a more comprehensive framework that would consider the impacts of intercultural exchange between students and host families. Future studies should draw on a larger sample among various geographical areas in the United States and beyond. They should consider a variety of host family profiles and various lengths of hosting. Furthermore, it would be beneficial to incorporate quantitative methods to measure specific $\mathrm{ABC}$ responses of the culture learning theory in detail. This would contribute greatly to the development of a new framework. 
For now, this study confirms that public diplomacy as promoted by the FLEX and YES programs indeed exposes international secondary school exchange students to American culture and values, and it gives an opportunity to American families to learn about foreign cultures. This is in line with the ECA's goals to promote mutual understanding between Americans and foreigners by learning about American culture, democratic institutions, and civic rights while in the United States. As per participants in this study, the value of intercultural exchange through citizen diplomacy can be supported by the fact that many host families who have hosted for over 20 years believed in the long-term benefits of the intercultural exchange. More studies among alumni and host families are needed to examine whether the impacts of the intercultural exchange hold true in the years following the exchange, and how alumni and host families use the newly acquired sociocultural skills due to this experience.

\section{REFERENCES}

American Councils for International Education. (n.d.-a). FLEX (Formerly A-SMYLE) application information. Retrieved March 21, 2019 from http://acsee.org/new/flex-program/\#sixth

American Councils for International Education. (n.d.-b). YES in Southeast Europe application information. Retrieved March 21, 2019 from http://acsee.org/new/yes-program/

Arksey, H., \& Knight, P. T. (1999). Interviewing for social scientists: An introductory resource with examples. SAGE.

Bachner, D., \& Zeutschel, U. (2009). Long-term effects of international educational youth exchange. Intercultural Education, 20(1-2), 45-58.

Bellamy, C., \& Weinberg, A. (2008). Educational and cultural exchanges to restore America's image. The Washington Quarterly, 31(3), 55-68.

Berry, J. W., Phinney, J. S., Sam, D., \& Vedder, P. (2006). Immigrant youth: Acculturation, identity, and adaptation. Applied Psychology: An International Review, 55(3), 303-332.

Brown, L. (2008). The incidence of study-related stress in international students in the initial stage of the international sojourn. Journal of Studies in International Education, 12(1), 5-28.

Brown, L., \& Graham, I. (2009). The discovery of the self through the academic sojourn. Existential Analysis, 20(1), 79-93.

Brown, L., \& Holloway, I. (2008). The initial stage of the international sojourn: excitement or culture shock? British Journal of Guidance \& Counselling, 36(1), 33-49.

Bureau of Educational and Cultural Affairs. (n.d.). What is hosting? Retrieved March 3, 2019 from https://eca.state.gov/programs-initiatives/host-high-school-student Bureau of Educational and Cultural Affairs. (2009). Evaluation of the youth exchange \& study program. Final report, August 2009. InterMedia.

Chamove, A. S., \& Soeterik, S. (2006). Grief in returning sojourners. Journal of Social Sciences, 13(3), 215-220. 
Chang, Y. Y. (2010). Are you my guest or my child? Mothers' uncertainties in interacting with their returnee children in China. Chinese Journal of Communication, 3(2), 167-184.

Creswell, J. W., \& Poth, C. N. (2018). Qualitative inquiry and research design: Choosing among the five approaches (4th ed.). SAGE.

Enloe, W., \& Lewin, P. (1987). Issues of integration abroad and readjustment to Japan of Japanese returnees. International Journal of Intercultural Relations, 11(3), $223-248$.

Farrugia, C. A. (2014). Charting new pathways to higher education: International secondary students in the United States. IIE Center for Academic Mobility Research Institute of International Education.

Grove, C. L., \& Hansel, B. (1983). Updated findings of the AFS impact study. AFS International/Intercultural Programs.

Hansel, B. (2008a). AFS long term impact study. Report 2: Looking at intercultural sensitivity, anxiety, and experience with other cultures. AFS International.

Hansel, B. (2008b). AFS long term impact study. Report 1: 20 to 25 years after the exchange experience, AFS alumni are compared with their peers. AFS International.

Harari, M. (1992). The internationalization of curriculum. In C. B. Klasek, B. J. Garavalia, \& K. J. Kellerman (Eds.), Bridges to the future: Strategies for internationalizing higher education. Southern Illinois University at Carbondale.

Hoersting, R. C., \& Jenkins, S. R. (2011). No place to call home: Cultural homelessness, self-esteem and cross-cultural identities. International Journal of Intercultural Relations, 35(2011), 17-30.

Hofstede, G. (1991). Cultures and organisations: Software of the mind. Harper Collins.

Institute of International Education. (2017). Globally mobile youth. IIE Center for Academic Mobility Research and Impact. https://p.widencdn.net/xguzsn/Globally-Mobile-Youth-Trends-in-InternationalSecondary-Students-in-the-United-States-2013-201

Izadi, F. (2016). US public diplomacy: A theoretical treatise. The Journal of Arts Management, Law, and Society, 46(1), 13-21.

Jang, D., \& Kim, D.Y. (2010). The influence of host cultures on the role of personality in the acculturation of exchange students. International Journal of Intercultural Relations, 34(4), 363-367.

Kim, Y. Y. (2001). Becoming intercultural: An integrative theory of communication and cross-cultural adaptation. SAGE.

Knight, J. (2017). Global: Moving from soft power to knowledge diplomacy. In G. Mihut, P. G. Altbach, \& H. Wit (Eds.), Understanding higher education internationalization. Global perspectives on higher education. Sense Publishers.

Knight, S. M., \& Schmidt-Rinehart, B. C. (2010). Exploring conditions to enhance student/host family interaction abroad. Foreign Language Annals, 43(1), 64-71.

Lyttle, A. D., Barker, G. G., \& Cornwell, T. L. (2011). Adept through adaptation: Third culture individuals' interpersonal sensitivity. International Journal of Intercultural Relations, 35(2011), 686-694. 
Marklein, M. B. (2014, July 8). International students flock to U.S. high schools. USA Today. https://www.usatoday.com/story/news/nation/2014/07/08/high-schoolforeign-international-students/12296741/

Moore, A. M., \& Barker, G. G. (2012). Confused or multicultural: Third culture individuals' cultural identity. International Journal of Intercultural Relations, 36(2012), 553-562.

National Museum of American Diplomacy. (2019). Discover diplomacy. Retrieved March 21, 2019 from https://www.state.gov/discoverdiplomacy

Organization for Economic Co-operation and Development. (2014). Education at a glance. https://www.oecd.org/edu/Education-at-a-Glance- 2014.pdf

Rodriguez, S., \& Chornet-Roses, D. (2014). How 'family' is your host family?: An examination of student-host relationships during study abroad. International Journal of Intercultural Relations, 39, 164-174.

Rohmann, A., Florack, A., Samochowiec, J., \& Simonett, N. (2014). 'I'm not sure how she will react": Predictability moderates the influence of positive contact experiences on intentions to interact with a host community member. International Journal of Intercultural Relations, 39(1), 103-109.

Schmidt-Rinehart, B., \& Knight, S. (2004). The homestay component of study abroad: Three perspectives. Foreign Language Annals, 37(2), 254-262.

Soeterik, S. M. (1998). Re-entry adjustment of high school exchange students to New Zealand: Cross-cultural transition within a loss and grief framework [Unpublished master's dissertation]. Massey University, Palmerston North, New Zealand.

Stake, R. E. (2005). Qualitative case studies. In N. K. Denzin \& Y. S. Lincoln (Eds.), The SAGE handbook of qualitative research (3rd ed., pp. 443-466). SAGE.

Sturges, J. E., \& Hanrahan, K. J. (2004). Comparing telephone and face-to-face qualitative interviewing: A research note. Qualitative Research, 4(1), 107-118.

Szkudlarek, B. (2010). Reentry-A review of the literature. International Journal of Intercultural Relations, 34(2010), 1-21.

Taylor, E., \& Merriam, S. (2008). Transformative learning theory. New Directions for Adult and Continuing Education, 2008(119), 5-15.

Thomas, A. (2005). Long-term effects of international students exchange programs. In W. Friedlmeier, P. Chakkarath, \& B. Schwarz (Eds.), Culture and human development: The importance of crosscultural research for the social science (pp. 303-320). Hove.

U.S. Citizenship and Immigration Services. (2018). § Sec. 62.25 Secondary school students. Exchange Visitor Program. https://www.uscis.gov/ilink/docView/22CFR/HTML/22CFR/0-0-0-1/0-0-03590/0-0-0-4552.html

Wan, T., Chapman, D., \& Biggs D. (1992). Academic stress of international students attending U.S. universities. Research in Higher Education, 33(5), 607-623.

Ward, C., Bochner, S., \& Furnham, A. (2005). The psychology of culture shock. Routledge.

Weichbrodt, M. (2014). Learning mobility: high school exchange programs as a part of international mobility. Children's Geographies, 12(1), 9-24. 
Wilson, A. H. (1993). A cross-national perspective on reentry of high school exchange students. International Journal of Intercultural Relations, 17(1993), 456-492.

Zhou, Y., Jindal-Snape, D., Topping, K., \& Todman, J. (2008). Theoretical models of culture shock and adaptation in international students in higher education. Studies in Higher Education, 33(1), 63-75.

MANCA SUSTARSIC, MA, is a PhD Candidate in the Educational Foundations department at University of Hawai'i at Manoa. Her major research interests lie in the area of international student mobility and secondary school exchange programs. Email: msustars@hawaii.edu 